\title{
A MULHER DO FIM DO MUNDO: A EVOLUÇÃO DOS DIREITOS HUMANOS DAS MULHERES
}

\section{Livia Martins Barbosa Pereira ${ }^{1}$}

RESUMO: O artigo científico pretende apresentar a evolução dos direitos humanos das mulheres no Brasil e no mundo. O estudo revelou a batalha travada pelas mulheres, através dos movimentos feministas, para se tornarem sujeitas de direitos, especialmente os direitos políticos, sociais e trabalhistas. No Brasil, além da igualdade entre gêneros trazida no texto da Constituição Federal de 1988, foi apresentada a evolução da proteção legislativa dada às mulheres, com a promulgação da Lei Maria da Penha e da Lei do Feminicídio.

Palavras-chave: Direitos humanos. Mulher. Violência doméstica. Feminicídio. Igualdade.

ABSTRACT: The scientific article intends to present the evolution of women's human rights in Brazil and in the world. The study revealed the battle waged by women, through feminist movements, to become subjects of rights, especially political, social and labor rights. In Brazil, in addition to the equality between genders introduced in the text of the Federal Constitution of 1988 , the evolution of the legislative protection given to women was presented, with the enactment of the Maria da Penha Law and the Feminicide Law.

Keywords: Human rights. Woman. Domestic violence. Femicide. Equality.

\section{INTRODUÇÃO}

Os direitos humanos são conquistados e construídos historicamente na sociedade. Os mesmos são frutos da prática reiterada de violações já vividas pelos homens e que servem como pontapé para a criação de normas capazes de evitar que tais ofensas ocorram novamente.

Trata-se, portando, de uma espécie de direito em constante evolução e transformação ao longo do tempo. Essa construção histórica dos direitos humanos é ressaltada por Gonçalves (2013, p. 68).

A humanidade está em constante processo de construção e reconstrução de direitos, que variam conforme o período histórico e as experiências vivenciadas pela humanidade. De maneira simplificada, pode-se dizer que direitos são criados para

\footnotetext{
I Mestra em Direito Econômico e Desenvolvimento pela Universidade Candido Mendes (2021); Advogada inscrita na OAB/RJ sob o no 217626; Bacharela em Direito pela Universidade Candido Mendes (2017). Discente em Licenciatura em Letras R2 (Língua Portuguesa e Literatura). E-mail: liviambpereira24@gmail.com.
} 
se evitar a perpetuação de determinadas violações, protegendo-se, assim, as pessoas de ofensas já anteriormente vividas. O direito surge como uma resposta àquelas violências que a sociedade entende injustificáveis e, portanto, deseja erradicar; como uma defesa aos abusos de poder. Os direitos humanos, nesta perspectiva, vão se construindo como um acúmulo crescente de parâmetros, de conteúdos reputados fundamentais, dos quais todo ser humano é titular.

\section{OS DIREITOS HUMANOS DAS MULHERES}

Os direitos das mulheres, no Ocidente, apenas começaram a ser as discutidos no século XVIII, dado o contexto da Revolução Francesa, em I789, cujo lema exigia liberdade, igualdade e fraternidade.

No que tange aos direitos humanos femininos, analisando-se retrospectivamente os direitos humanos no mundo, vê-se que a Declaração dos Direitos do Homem e do Cidadão, cujo texto data de 1789 , sequer mencionava as mulheres. A inexistência de qualquer proteção à mulher no texto da Declaração dos Direitos do Homem e do Cidadão evidencia que, à época, as mulheres não eram consideradas indivíduos merecedores de reconhecimento dos seus direitos básicos.

Em contraposição à Declaração dos Direitos do Homem e do Cidadão, em I79I, foi proposto à Assembléia Nacional da França, durante a Revolução Francesa (1789-1799), a Declaração dos Direitos da Mulher e da Cidadã. Tal declaração foi proposta por Marie Gouze, sob o pseudônimo Olympe de Gouges. O texto demonstrava a desigualdade existente entre homens e mulheres e criticava a condição de opressão a que as mulheres eram submetidas na época. Marie Gouze foi guilhotinada em 1793.

Aos poucos, através de muita luta feminista, o tema da igualdade foi ganhando força na cena mundial e as mulheres começaram a serem incluídas como sujeitas de direitos como exemplifica Fernandes (2015. p.18):

\footnotetext{
A luta dos movimentos feministas, a reivindicação do direito ao voto e o ingresso da mulher no mercado de trabalho modificaram aos poucos sua posição na sociedade. Assim, a partir do século XX, foram publicados Tratados e Convenções abordando temas específicos relacionados às mulheres: Convenção Internacional para a Repressão ao Tráfico de Mulheres e de Crianças (Genebra, 192I); Convenção Interamericana sobre a Nacionalidade da Mulher (Organização dos Estados Americanos - OEA, Montevidéu, 1933); Convenção Interamericana sobre a Concessão de Direitos Políticos à Mulher (Organização dos Estados Americanos - OEA, Bogotá, 1948); Convenção da Organização Internacional do Trabalho n. 89, sobre o trabalho noturno de mulheres (São Francisco, 1948); Convenção da Organização Internacional do Trabalho n. Ioo, sobre a igualdade de remuneração para mão de obra masculina e para mão de obra feminina por um trabalho de igual
} 
valor (Genebra, 195I); Convenção Internacional sobre os Direitos Políticos da Mulher (Organização das Nações Unidas - ONU, Nova York, 1953); Convenção da Organização Inter- nacional do Trabalho n. I03, sobre o amparo à maternidade (Genebra, 1952); Convenção da Organização Internacional do Trabalho n. III, sobre a discriminação em matéria de emprego e profissão (Genebra, 1968); Convenção Internacional sobre a Nacionalidade da Mulher Casada (Organização das Nações Unidas - ONU, Nova York, 1969); Convenção da Organização Internacional do Trabalho n. I7I, relativa ao trabalho noturno (Genebra, 1990); Declaração de Pequim, assinada na 4a Conferência Mundial sobre as Mulheres - ação para a igualdade, desenvolvimento e paz (Pequim, 1995); Protocolo Adicional à Convenção Internacional contra Crime Organizado Transnacional, relativo à Prevenção, Repressão e Punição do Tráfico de Pessoas, em especial Mulheres e Crianças (Organização das Nações Unidas - ONU, Nova York, 200o).

Os diplomas acima elencados por Fernandes foram de grande contribuição para que houvesse o fortalecimento da ideia de que as mulheres eram igualmente sujeitos de direitos e deveres, sobretudo quanto ao reconhecimento de seus direitos políticos, sociais e trabalhistas. Fundamental, ainda, destacar a luta pelo direito ao voto, posto que as mulheres, já inseridas num contexto de trabalho na sociedade, atuantes em todos os aspectos da vida social cotidiana, deveriam ter seus direitos políticos assegurados.

Embora sejam de valiosa importância, faz-se necessária a ressalva de que, com exceção da Declaração de Pequim (1995), os instrumentos internacionais de direitos humanos tratavam de temas específicos e não da igualdade propriamente dita entre homens e mulheres.

A Declaração de Pequim, nascida da Quarta Conferência Mundial sobre as Mulheres em 1995, tinha por objetivo a promoção da igualdade, do desenvolvimento e da paz para todas as mulheres, em todos os lugares do mundo, no interesse de toda a humanidade.

No Brasil, a mulher somente passou a ter o direito ao voto em 1932. Apesar de poderem votar e serem votadas, dentre as mulheres que se candidataram à Assembleia Constituinte em 1933, apenas uma delas, Carlota Pereira de Queiroz, conseguiu ser eleita pelo Estado de São Paulo como deputada federal.

A Constituição de 1934 trazia em seu texto a vedação às diferenças salariais para um mesmo trabalho por motivo de sexo, proibia o trabalho de mulheres em indústrias insalubres, vedava a demissão motivada pela gravidez, garantia a assistência médica e sanitária às gestantes, bem como o descanso antes e depois do parto, assegurados através da Previdência Social. 
A Declaração Universal de Direitos Humanos, proclamada pela Assembléia Geral das Nações Unidas, em io de dezembro 1948, prevê a igualdade jurídica entre homens e mulheres e, ainda que de maneira incipiente, abre caminho para o reconhecimento das mulheres como seres humanos detentores de proteção legal e estatal.

Nesse sentido, vale destacar algumas partes trazidas no preâmbulo da Declaração Universal de Direitos Humanos (1948), nas quais há a expressa menção à proteção da mulher e o seu reconhecimento enquanto sujeito de direitos.

(...) o reconhecimento da dignidade inerente a todos os membros da família humana e de seus direitos iguais e inalienáveis é o fundamento da liberdade, da justiça e da paz no mundo

(...) Considerando que os povos das Nações Unidas reafirmaram, na Carta, sua fé nos direitos fundamentais do ser humano, na dignidade e no valor da pessoa humana e na igualdade de direitos do homem e da mulher e que decidiram promover o progresso social e melhores condições de vida em uma liberdade mais ampla (...)

Seguindo adiante no texto da Declaração de Direitos Humanos (1948), destaca-se o artigo ı6, cuja redação, para além de ressaltar que homens e mulheres gozam de direitos iguais em relação ao casamento e à dissolução do mesmo, estabelece que a família deva ter a proteção da sociedade e também do Estado.

I. Os homens e mulheres de maior idade, sem qualquer restrição de raça, nacionalidade ou religião, têm o direito de contrair matrimônio e fundar uma família. Gozam de iguais direitos em relação ao casamento, sua duração e sua dissolução.

2. O casamento não será válido senão com o livre e pleno consentimento dos nubentes.

3. A família é o núcleo natural e fundamental da sociedade e tem direito à proteção da sociedade e do Estado.

É importante contextualizar a época em que a Declaração de Direitos Humanos (1948) foi escrita para compreender a ausência de uma individualização mais abrangente de quem é o Humano sujeito de tais direitos e proteções. Chegava ao fim, em 1945, a Segunda Guerra Mundial, com milhões de pessoas mortas num cenário catastrófico de violações dos direitos fundamentais dos homens. Havia pressa, portanto, em criar um ambiente seguro e de proteção à vida.

Ainda que aparentemente deficitária sob os olhares atuais, a DUDH (1948) é um documento cujo objetivo - a proteção do ser humano - pode ser alcançado através da 
interpretação expansiva do seu texto para adaptá-lo às nuances atuais existentes, para além do caráter biológico de simplesmente homem-mulher.

No Brasil, a Emenda Constitucional no 45 conferiu ao artigo $5^{\circ}$, parágrafo $3^{\circ}$, da Constituição Federal de 1988 status constitucional aos Tratados e Convenções de Direitos Humanos aprovados pelo Congresso Nacional. Dessa maneira, para que os tratados e convenções internacionais passem a ter força constitucional, há a exigência de seguir o rito de votação em cada Casa e dois turnos, por três quintos dos votos dos respectivos membros.

Os instrumentos de Direitos Humanos promulgados antes da Emenda Constitucional $\mathrm{n}^{\mathrm{o}} 45$ e sem o procedimento especificado anteriormente, segundo o entendimento do STF, possuem equivalência à norma supra legal, ou seja, hierarquicamente os mesmos estão abaixo da Constituição Federal de 1988, porém acima da legislação ordinária.

\section{A PROTEÇÃO LEGAL DA MULHER NO BRASIL}

A Constituição Federal de 1988, seguindo os preceitos da Declaração Universal de

Direitos Humanos de 1948, prevê a dignidade da pessoa humana e, inclusive, assegura claramente a igualdade entre homens e mulheres.

Art. $5^{\circ}$ Todos são iguais perante a lei, sem distinção de qualquer natureza, garantindo-se aos brasileiros e aos estrangeiros residentes no País a inviolabilidade do direito à vida, à liberdade, à igualdade, à segurança e à propriedade, nos termos seguintes: I - homens e mulheres são iguais em direitos e obrigações, nos termos desta Constituição.

Insta ressaltar que a igualdade entre homens e mulheres é um fator determinante no exercício da democracia. Dessa maneira, a Lei 9.00o/95 e a Lei 9.504/97 prevêem ações afirmativas com a criação de cotas para aumentar o número de mulheres na política, tanto candidatas quanto eleitas para as casas legislativas.

E, embora o Direito tenha, sim, gênero - frisa-se masculino -, seja majoritariamente criado por homens e historicamente voltado às suas necessidades, a crescente ocupação das mulheres nos cargos legislativos tende a equalizar a distorção histórica existente.

Mergulhão (2015. p. 127) ressalta que o ordenamento jurídico deve harmonizar com os preceitos e princípios constitucionais. 
A aplicação substantiva da Constituição demanda a aplicação de seus preceitos, e princípios, sob o ordenamento jurídico, como um todo. Inadmissível se compartimentar criando princípios, e subprincípios incompatíveis com a aplicação direta dos Princípios constitucionais, dentre os quais os Princípios da Dignidade da Pessoa Humana e da Solidariedade.

Outro aspecto de suma importância dos direitos humanos das mulheres é o combate à violência de gênero. Conforme o exposto no preâmbulo da Declaração Universal de Direitos Humanos (1948), a Constituição Federal de 1988 dispõe no artigo 226, caput, que "a família, base da sociedade, tem especial proteção do Estado".

Seguindo tal raciocínio, destaca-se que o mesmo artigo, em seu parágrafo $8^{\circ}$ determina que "O Estado assegurará a assistência à família na pessoa de cada um dos que a integram, criando mecanismos para coibir a violência no âmbito de suas relações.”. Ora, se a Constituição da República traz em seu texto que o Estado deve proteção e assistência à cada membro da família, devendo inclusive criar mecanismos a fim de evitar a violência dentro das unidades familiares, não restam quaisquer dúvida sobre a relevância da criação da Lei Maria da Penha ou de qualquer outra lei de proteção à mulher para a sociedade como um todo.

A existência da doméstica contra a mulher é um fato público, notório e incontestável. Logo, se há a necessidade primária de evitar que ela exista, bem como havia uma lacuna legal até a elaboração da Lei II.340/2006, não há desrespeito ao princípio da igualdade jurídica entre homens e mulheres prevista na CRFB/88.

Para além da proteção das mulheres no ambiente doméstico-familiar, a previsão constitucional abre caminho para uma punição específica para os agressores, posto que não se trate de um crime generalista, mas sim com uma vítima específica. Destaca-se que a proteção dada à mulher na Lei Maria da Penha não recai apenas nos relacionamentos afetivos ou sem laços de consanguinidade. A proteção legal vale para todas as mulheres em situação de violência doméstica e familiar, ou seja, o agressor pode ser parente (pais, avós, irmãos, tios) ou pode ser atual e ex-companheiro, namorado, marido. Outro ponto fundamental é a desnecessidade de que haja convivência entre vítima e agressor sob o mesmo teto.

Em que pese a previsão constitucional expressa de que homens e mulheres são “iguais” perante a lei, a carta magna não foi suficientemente eficaz para erradicar a 
discriminação de gênero e a violência que dela resulta, como demonstra Fernandes (2015. p. 4I):

\begin{abstract}
A tradicional fórmula genérica de igualdade de "todos" perante a lei não serviu para eliminar a discriminação contra as mulheres. A Constituição Federal de I988, atenta aos movimentos de valorização da mulher, previu textualmente a igualdade de homens e mulheres em direitos e obrigações. E o reconhecimento dessa igualdade formal foi o primeiro passo, retirando do ordenamento diferenças discriminatórias. Contudo, a efetividade da igualdade exige algo mais.
\end{abstract}

Desta forma, diante da especificidade das relações familiares e da convivência entre agressor e vítima, havia necessidade da elaboração de uma proteção eficaz para impedir que aquele agressor viesse a perpetuar o comportamento delituoso dentro da unidade familiar.

Ao crime com resultado morte praticado contra uma mulher em situação de violência doméstica ou familiar ou em razão de menosprezo ou discriminação à condição de ser mulher é dado o nome de feminicídio. Este crime revela a escalada da violência cotidiana contra a mulher ao expor a forte misoginia por parte dos homens. A coisificação da mulher torna, para o agressor, a vida da vítima menos importante, já que ele detém a sua posse e acredita que pode fazer o que bem entender com ela.

É mais comum encontrar notícias de casos de feminicídio no contexto familiar, pois a violência é usada com a intenção de colocar as mulheres em posição de inferioridade, mantendo-as submissas em relação ao homem - o chefe da casa. Assim, a dominação do homem se perpetua por gerações e torna-se algo "cultural". Mas isso não quer dizer que, fora da intimidade dos relacionamentos, não existam cerceamentos de direitos, de oportunidades, discriminação e dominação nos demais ramos da sociedade.

Nestes casos, o machismo se manifesta como diferença salarial, número inferior de mulheres em algumas carreiras ou extremamente superior em outras, como a educação infantil e os trabalhos domésticos. Tais situações de inferioridade e, às vezes, ódio contra a mulher também dão causa às suas mortes e estes crimes de igual maneira serão considerados como feminicídios.

Nota-se, então, que o tipo penal em questão aplica-se em relação à misoginia como motivação, não obrigatoriamente no contexto familiar ou doméstico, como aponta Mello (2017. P. 32):

A definição de feminicídio/femicídio mais adequada e útil para a análise jurídicopenal seria, portanto, o assassinato de mulheres baseado no gênero, incluindo não 
apenas o assassinato por parceiros íntimos, mas também a morte intencional por parceiros não íntimos, que tenha sido motivada em razão de gênero.

Há uma preferência da doutrina pelo vocábulo femicídio por ser a tradução mais fiel do inglês femicide e, portanto, possuir uma significação globalizada e de fácil entendimento. No Brasil, no entanto, o legislador optou pelo termo feminicídio e este se popularizou com a publicação da Lei 13.104/2015. Este diploma legal altera o artigo I2I do Código Penal incluindo, no parágrafo $2^{\circ}$, o inciso VI, para qualificar o homicídio contra a mulher. A alteração legal prevê um aumento de pena de um terço até a metade caso a mulher seja morta durante a gravidez ou nos três meses posteriores ao parto; quando a vítima é menor de I4 anos ou maior que 6o ou é deficiente; ou quando o crime é cometido na presença de ascendente ou descendente da mulher. Outra providência tomada pela Lei 13.104/2015 é a alteração do artigo Io da Lei 8.072/1990 para incluir de maneira inequívoca o feminicídio no rol dos crimes hediondos por se tratar de homicídio qualificado.

\section{CONCLUSÃO}

O presente artigo científico teve como principal objetivo traçar um panorama da

evolução dos direitos humanos das mulheres, principalmente no que diz respeito aos direitos reconhecidos e garantidos às mulheres no Brasil.

O estudo realizado revelou que, em que pese o avanço da proteção legal à mulher, ainda há grande disparidade entre homens e mulheres. Merece destaque a informação de que a violência contra a mulher ainda ocorre rotineiramente e é muitas vezes negligenciada. Nem sempre é dada a devida importância por parte da sociedade nem das autoridades responsáveis por evitá-la, dando ensejo algumas vezes a desfechos trágicos, como é o feminicídio.

Aqui, vale ressaltar, não há preferência para o sexo feminino, nem tão pouco violação ao direito constitucional de igualdade entre homens e mulheres. Ocorre, no entanto, uma proteção legal para frear a misoginia que violenta e mata mulheres há anos no Brasil. Nesse sentido, foi demonstrada uma preocupação das entidades mundiais de Direitos Humanos, no intuito de recomendar que fossem elaboradas leis específicas sobre o tema para que os agressores fossem punidos com rigor e justiça. Além disso, que fossem 
estabelecidas medidas protetivas e de urgência para que a vítima tivesse proteção real, como ocorre com a Lei Maria da Penha.

Ainda há discussões sobre a eficácia da Lei 13.104 de 2015, mas, em conjunto com a Lei Maria da Penha e as demais leis e medidas governamentais, criou-se uma rede que possibilita que o aparato policial e judiciário esteja voltado para atender as vítimas até que, um dia, a violência contra a mulher deixe de ser realidade.

Destarte, há a esperança de que este artigo científico seja capaz de promover o debate a respeito dos direitos das mulheres no Brasil e no mundo, ainda que em pequenas dimensões. Espera-se que, um dia, a igualdade jurídica e social entre homens e mulheres seja de fato alcançada.

\section{REFERÊNCIAS}

ANDRADE, Vera Regina Pereira de. A Soberania Patriarcal: O Sistema De Justiça Criminal. Disponível em: 〈https://periodicos.ufsc.br/index.php/sequencia/article/view/15185 〉. Acesso em 06.02.2021.

BIANCHINI, Alice. Lei Maria da Penha: Lei n. 1r.340/2006: Aspectos assistenciais, protetivos e criminais da violência de gênero. - 4. ed. - São Paulo: Saraiva Educação, 2018. (Coleção saberes monográficos). 305 p.

BITTAR, Eduardo C. B.; ALMEIDA, Guilherme A. Curso de Filosofia do Direito. São Paulo: Grupo GEN, 2020. 910 p.

BRASIL. [Constituição Federal (1988)]. Constituição da República Federativa do Brasil. Brasília, DF: Senado Federal, 2020. 500 p.

BRASIL. Lei ir.340 (Lei Maria da Penha), de o7 de agosto de 2006. Cria mecanismos para coibir a violência doméstica e familiar contra a mulher, nos termos do§ $8^{\circ}$ do art. 226 da Constituição Federal. Diário Oficial da União, Brasília, DF, o8 ago. 2006. 
BRASIL. Lei 13.104, (Lei do Feminicídio), de 09 de março de 2015. Altera o art. I2I do DecretoLei no 2.848, de7 de dezembro de 1940-Código Penal, para prever o feminicídio como circunstância qualificadora do crime de homicídio, e o art. Io da Lei 8.072, de 25 de julho der99o, para incluir o feminicídio no rol dos crimes hediondos. Diário Oficial da União, Brasília, DF, o9 mar. 2015.

CARNIO, Henrique Garbellini. Direito e Antropologia. São Paulo: Editora Saraiva, 2020. I74 p.

CEJUS. A violência doméstica fatal: O problema do feminicídio íntimo no Brasil.

Disponível em:

http://www.compromissoeatitude.org.br/wpcontent/uploads/2015/o4/Cejus_FGV_femin icidiointimo2015.pdf >. Acesso em 15. 10.2020.

DIAS, Maria Berenice. A lei Maria da Penha na justiça. 3. ed. São Paulo: Revista dosTribunais, 2012.

DIAS, Sandra Pereira Aparecida. Um breve histórico da violência contra a mulher. 26 jan. 20I0. Disponível em: <http://araretamaumamulher.blogs.sapo.pt/16871.html >. Acesso em 02.02.2021.

FERNANDES, Valéria Diez Scarance. Lei Maria da Penha: O Processo Penal no Caminho da Efetividade. Rio de Janeiro: Grupo GEN, 2015.

GONÇALVES, Tamara Amoroso. Direitos humanos das mulheres e a Comissão Interamericana de Direitos Humanos. São Paulo: Saraiva, 2013. 330 p.

JESUS, Damásio de. Violência contra a mulher: aspectos criminais da Lei n.II.340/2006. 2. ed. - São Paulo: Saraiva, 2015. 104 p. 
MELLO, Adriana Ramos de. Feminicídio: Uma análise sócio-jurídica da violência contra a mulher no Brasil. Rio de Janeiro: Editora GZ, 2- Ed./2017. 204 p.

MENDES, Soraia da Rosa. Processo Penal Feminista. São Paulo: Editora Atlas, ine Ed./202o. $185 \mathrm{p}$.

MERGUlhãO, Maria Fernanda Dias. Indenização Integral na Responsabilidade Civil. Rio de Janeiro: Grupo GEN, 2015. I59 p.

O Mapa da Violência 2015: Homicídios de Mulheres no Brasil. WAISELFISZ, Julio Jacobo. Disponível em: < https://www.mapadaviolencia.net.br/mapazor5_mulheres.php>. Acesso em 07.02.2021.

OEA. Comissão Interamericana de Direitos Humanos. Relatório no 54/2001: caso 12.051. Disponível em: < https://cidh.oas.org/annualrep/200oport/I2051.htm >. Acesso em 07.02 .2021 .

ONU. Organização das Nações Unidas. Declaração Universal dos Direitos Humanos. Adotada e proclamada pela Assembleia Geral das Nações Unidas (resolução 217 A III) em ıo de dezembro 1948. Disponível em: < https://www.unicef.org/brazil/declaracaouniversal-dosdireitos-humanos >. Acesso em 07.02.2021.

PRIORE. Mary Del (org.). História das mulheres no Brasil. ı.ed. São Paulo: Contexto, 2oro. 